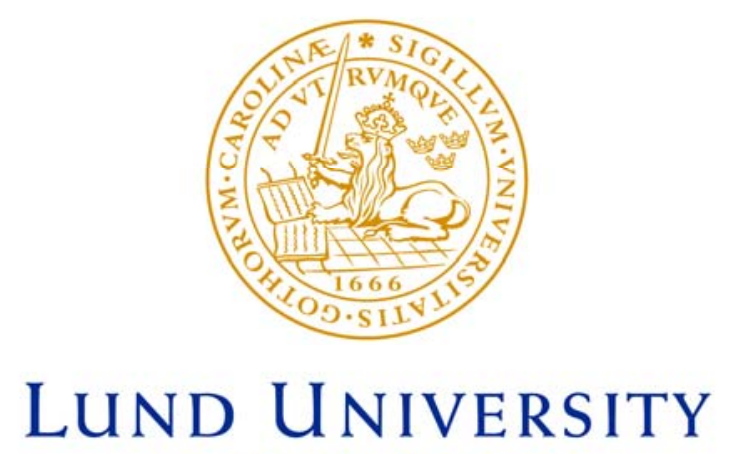

Faculty of Medicine

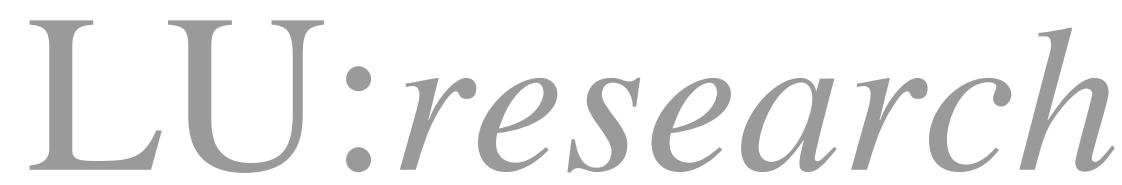

Institutional Repository of Lund University

This is an author produced version of a paper published in European radiology. This paper has been peer-reviewed but does not include the final publisher proof-corrections or journal pagination.

Citation for the published paper:

Fork, Frans-Thomas and Aabakken, Lars.

"Capsule enteroscopy and radiology of the small intestine"

Eur Radiol, 2007, Sep 18; [Epub ahead of print]

http://dx.doi.org/10.1007/s00330-007-0718-7

Access to the published version may require journal subscription.

Published with permission from: Springer 
Capsule Enteroscopy and Radiology of the Small Intestine

\section{Capsule Enteroscopy and Radiology of the Small Intestine}

Frans-Thomas Fork and Lars Aabakken,

Dr. Frans-Thomas Fork, MD, PhD (correspondence)

Department of Diagnostic Radiology

Malmö University Hospital,

SE-205 02 Malmoe, Sweden.

Email: thomas.fork@med.lu.se.

Phone: +46- 40- 3388 63;

Fax: $\quad+46-40-337878$

Dr. Lars Aabakken, MD, PhD

Department of Gastroenterology,

Rikshospitalet University Hospital

N-0027 Oslo, Norway

Email: larsaa@medisin.uio.no

Phone: +4723072400

Fax: $\quad+4723072008$ 
Capsule Enteroscopy and Radiology of the Small Intestine

\begin{abstract}
In a very few years, the video capsule for small bowel enteroscopy has gained widespread clinical acceptance. It is readily ingested, disposable, and allows for a complete, low-invasive endoscopic examination of the entire mucosa of the small bowel. It is a patient-friendly method and a first line procedure in the difficult evaluation of obscure gastrointestinal bleeding. It has the highest proven figure of diagnostic sensitivity for detecting lesions of the mucosa, irrespective of aetiology. The limitations of capsule endoscopy include difficulty in localizing mucosal lesions anatomically and its restricted use in patients with dysphagia, strictures or motor dysfunction. Strictures, transmural and extra-mural lesions in patients with small bowel Crohn's disease are evaluated by MRI- enterography and CT-enterography.
\end{abstract}


Imaging of the small bowel was, until recently, the responsibility of the radiologist, who, in dedicated centres, offered the patient not just a small-bowel follow-through with single exposures over time, but a dedicated, real time, fluoroscopic examination of a well distended small bowel, displayed in double-contrast and documented on spot films (1). This enteroclysis technique, well accepted by gastroenterologists, significantly improved both the detection of mucosal disease and the mapping of involved bowel segments. However, the duration of the examination, discomfort related to nasojejunal intubation and infusion of large volumes of contrast and distension materials, be it methyl cellulose or air (2), reduced general acceptance and dissemination of this method (3).

A complete endoluminal examination was until recently only possible with intra-operative endoscopy, and limited Sonde enteroscopy (4). Hence the mucosa remained difficult to inspect visually due to the length and complexity of the small bowel until the wireless, peroral video capsule for enteroscopy, VCE, was introduced at the 2000 Digestive Diseases Week in San Diego, California (5). Since then, more than 340000 examinations (Given Imaging Ltd, Yoqneam, Israel, Spring 2006) have been performed worldwide with an overall complication rate of only $0.75 \%$ (6). Based on meta-analyses of published clinical results VCE has evolved to be the first line procedure in many hospitals (7-13), keeping small bowel radiology as method of choice for patients who cannot take the capsule (13). In order to understand the diagnostic algorithm of modern small bowel examination we will discuss the video capsule technique, its indications and contraindications, advantages and disadvantages, types of true and false lesions and comparative studies of VCE and radiological methods of investigation of the small intestine.

\section{The video capsule}

VCE was primarily developed for examination of small bowel mucosa $(14,15)$. Rapid technical refinement has since resulted in a dedicated capsule for the oesophagus, and recently capsules for the study of both stomach and colon (16).

The capsule measures 11 by $27 \mathrm{~mm}$ and includes a light source and a camera inside a clear, transparent dome, batteries and a radio-transmitter (Figure 1). Whilst ushered forward by peristalsis the capsule transmits images continuously at two frames per second for around eight hours, a total of more than 60.000 images. The image has a $140^{\circ}$ field of view, a focus depth of 1-30 mm, and an 8:1 magnification (17). An array of eight external detectors, applied to the abdominal wall, receives the images for storage in a solid state data recorder. 
The recorder is powered by two 5D cell silver oxide batteries (Figure 2). The video is subsequently downloaded into a computer workstation for evaluation.

The examination is presented as a continuous video film in single or multiple picture view, thus reducing the time of reading at the workstation from around 90 minutes down to 45 minutes (18). The software is constantly upgraded and the latest version includes a localizing system (figure 3 ) as well as a blood (red colour) detector capability.

\section{The procedure}

The procedure is considered easy by patients, is non-invasive, and usually performed as an ambulatory examination. After a 12 hour fast the patient ingests the capsule with a whole glass of water, leaves the department after fifteen minutes and is encouraged to conduct a regular daily activity. Free liquid is allowed after two hours, and food after another two. The trans-pyloric time ranges 8-184 minutes, average 61 minutes, the small bowel transit time, 183-393 minutes, average 251 minutes, and the time to the caecum is 4-48 hours (17).

An incomplete VCE may be caused by gastric retention, slow bowel transit and residual small bowel content blurring vision (19). Efforts are being made to control the transit of the capsule and to optimize cleansing of the small bowel $(20,21)$. The consensus at this point is that the use of bowel preparations and pro-kinetics may reduce the number of failed examinations, but the optimal solution has yet to be found (22).

\section{Scope and limitation of of VCE imaging}

As the optical parameters of the capsule provide superb images of the mucosal lining with high resolution down to an individual villous structure, even a limited number of missing villy is regularly disclosed as a minimal area of denudation. The clinical importance of such findings are still unclear and under investigation. It expresses, however, the potential of VCE to depict superficial and tiny lesions. Mucosal lesions such as edema, erosions, aphtae or ulcers of various depth are well displayed by VCE imaging (23). What is more, any change in colour, surface structure and gut lumen width, facilitates lesion detection by VCE as with classical endoscopy. Further lesions include angiodysplasia, haemangioma, varices, anastomotic strictures, benign, early and advanced malignant tumours (24). 
Lesions beyond the mucosal lining cannot be diagnosed by VCE. Thus, extra-mucosal small bowel wall disorders, be it leiomyoma, carcinoid tumour or GIST, cannot be distinguish from an abutting, true extra-intestinal lesion, as any dislocation of a bowel loop is unobtrusive at VCE. Indentations of the bowel are notoriously difficult to assess as extrinsic or intramural processes. Furthermore, functional aspects of small bowel, viz. motility disorders, fixation, stiff segments, etc., can not be evaluated on a VCE study.

\section{Indications and results for VCE}

\section{$\underline{\text { Small bowel bleeding }}$}

The prime indication for VCE is investigation of occult gastrointestinal bleeding (OGIB) (25). Today its role has widened to include any disease or condition related to the mucous membrane of the small bowel. Some indications now evidence based, while others are less well established.

In patients with gastrointestinal bleeding, obscure, occult or macroscopic, multiple VCEseries have shown a significant increase in the diagnostic yield (Figure 5) over other imaging modalities, ranging between $39 \%$ and $90 \%(26,27)$. As it has also been shown that the yield increases with a narrowing time gap between the bleeding episode and the VCE, an international consensus group proposed a reversed order of examinations after negative classical endoscopies, i.e. VCE before any enteroscopy. Based on published results the sensitivity of VCE in small bowel bleeders is approximately $90 \%$ and the specificity $95 \%$ (28).

Several prospective, controlled trials on the comparative clinical importance of VCE in the management of patients with small bowel haemorrhage have shown that VCE has the highest diagnostic yield and is significantly superior to small bowel radiology as well as to push enteroscopy (26-29). In patients with OGIB, VCE has a calculated incremental yield over push enteroscopy and small bowel barium radiology for clinically significant findings of $\geq 30 \%$, mainly ascribed to visualization of additional vascular and inflammatory lesions by VCE (22). However, small bowel radiology still results in a change in clinical management in approximately $10 \%$ of patients, although its overall positive yield may be less than $20 \%$ (30). 


\section{$\underline{\text { Small bowel Crohn's disease }}$}

VCE signs of early Crohn's disease include minute mucosal lesions such as villous denudation, aphthoid ulcerations, or erosions distributed from the pylorus to the distal ileum (Figure 6). These are diagnosed significantly more often by VCE than by any radiographic method, including CT-enteroclysis (31,32). "New" lesions, compatible with Crohn's disease, but not identified by other imaging modalities, may be revealed in $40 \%$ to $65 \%$ of VCE examinations (33). A consensus group estimated the incremental diagnostic yield to range between $15 \%$ and $44 \%$ (34), at least for detecting the mucosal breaks of early Crohn's disease In patients with known Crohn's disease, additional lesions not detected by other modalities may be disclosed by VCE in $47 \%$ of cases and lesions detected by other modalities may be ruled out in $16 \%$ of cases (35).

As Crohn's disease most often expresses itself in the distal part of the small bowel, visualization of the terminal ileum and the ileo-cecal valve is best gained by ileo-colonoscopy and CT-enteroclysis (36).

The clinical impact of the documented increase in quantity of lesions and their axial spread, unveiled by VCE in patient with Crohn's disease, has yet to be shown. However, repeat VCE may guide therapy by documenting mucosal response to medical and surgical treatment of known disease (34).

In patients with Crohn's disease, complicating strictures are frequently found. These patients are excluded from a capsule enteroscopy, a fact that has to be considered when comparing results from various investigative modalities. Up to an $8 \%$ risk of capsule impaction in a complicating stricture has been reported $(6,37)$. Nevertheless, VCE seems to be slightly more sensitive than MR-enteroclysis in both suspected and in established Crohn's disease. On the other hand, MRI is pre-eminent in imaging the degree of inflammation, in identifying transmural Crohn's disease, in showing the existence of strictures, enteric fistulae, and secondary mesenteric manifestations (38-41). The corresponding ability of VCE to delineate transmural complications is limited, as VCE cannot disclose changes in the mesenteric fibrofatty tissue, hyperaemia and involvement of the lymphatic systems. It seems therefore justified to conclude that VCE, enteroclysis with MRI and CT are complementary tools for a global understanding of small bowel Crohn's disease $(42,43)$ the first capable of detecting mucosal lesions (44), the latter two transmural and extra-intestinal manifestations $(45,46)$. CTenteroclysis has been reported to have less favourable results (47). 
VCE in children with suspected Crohn's disease is usually successful $(48,49)$. The capsule can be ingested by children above the age of eight, but has to be deposited endoscopically into the duodenum in younger patients.

Based on accumulated clinical data gastroenterologists consider VCE cost effective in patients with Crohn's disease through early diagnosis and treatment (50).

\section{Inherited polyposis syndromes}

Not only the large bowel and rectum but also the small bowel is afflicted in patients with inherited polyposis syndromes. Although the majority of the polyps are insignificant in size, some are big (Figure 7), and the sheer number of lesions puts the patient at an increased risk of malignancy. It is therefore important to include the small bowel in a survey programme for these patients. The VCE offers such a diagnostic capability $(51,52)$.

\section{$\underline{\text { Drug effects }}$}

Drug induced enteropathy, for instance related to NSAID use, is seen as mucosal erythema, erosions, small ulcers and web like strictures, can be readily diagnosed and monitored by VCE (53).

\section{$\underline{\text { Small bowel tumours }}$}

The majority of VCE-detected small bowel tumours have been diagnosed in patients examined for occult gastrointestinal bleeding, with an increase in yield from $3 \%$ before the VCE, to $8 \%$ thereafter (54).

\section{$\underline{\text { Celiac disease }}$}

In celiac disease, a gradual decomposition of the villous structures is seen (Figure 8), viz. from scalloping and mosaic pattern down to complete villous atrophy, i.e. flat, nodular mucosa without folds $(55,56)$. As VCE provides images with a high definition and magnification, it readily unveils not only the quantity and quality of these lesions, but also their distribution. VCE has thus the potential to monitor treatment in patients with known disease and to be a confirming test in sero-positive patients (57). Furthermore, VCE has the utility of delineating ulcerative jejunitis and complicating small bowel lymphoma. 


\section{$\underline{\text { Abdominal pain }}$}

The role of capsule endoscopy in patients with chronic abdominal pain and/or irritable bowel syndrome-like symptoms is still unclear, as the diagnostic yield in these cases is low (37).

\section{Patency capsule}

Patients with severe dysphagia and delayed pyloric transit may have the capsule deposited in the duodenum via gastroscopic intubation. Patients with known or suspected small bowel stenosis, and those having had extensive abdominal surgery, are recommended to have a patency test with a radio-opaque, sham capsule prior to a planned VCE (58). This "patency capsule", equal in size to the diagnostic capsule, contains a radio frequency identification tag. If it becomes impacted, it is designed to dissolve and pass on through the stricture. A free passage is proven by the delivery of the capsule within forty hours and/or proved absent by abdominal fluoroscopy or external scanning after 36 hours. A retained patency capsule indicates a stenosis and a planned VCE may have to be cancelled (18). However, initial studies indicate that the patency capsule can itself get impacted due to incomplete dissolving. Until more experience has been gained, VCE should be avoided in pregnant patients and in patients requiring MR imaging before the capsule is expelled. The risk that the capsule might interfere with the function of a pacemaker is probably low (59) and no clinical cases have been reported.

\section{Algorithm of examination procedures}

Based on the $1 \%$ overall risk of a capsule getting stuck (6) and the proven shortcomings of radiology of the small bowel to exclude a stricture, the medical community of gastroenterologists today discusses the use of VCE as a first line investigation of the small bowel, at least after a patency test, instead of being last in line $(6,60)$.

\section{Further aspects of VCE and radiology}

In the pre-capsule era, the diagnostic work-up in patients with unexplained iron-deficiency anaemia included radiology of the small bowel, most often conducted as a tube enteroclysis or dedicated single contrast enterography, with a diagnostic yield of $10 \%$ to $20 \%$ only (61). The documented increase in diagnostic yield after the introduction of the VCE in 2001, resulted in its rapid clinical acceptance for investigation of patients with recurrent gastrointestinal bleeding of obscure origin, primarily in those with negative small bowel barium enema studies (62), gastroscopy and colonoscopy (51). The inferior results achieved by radiology 
may be attributed to perceptional errors by the radiologist, or enterographic studies being technically suboptimal (63).

Positive findings on enteroclysis include cases with motility disorder and mucosal abnormalities, adhesions, filling defects and masses, strictures and small bowel diverticulosis $(64,65)$. The apparent superiority of VCE over enterographic studies may, at least in part, be due to selection bias, as patients with positive radiologic findings often are excluded from VCE (66). Thus a comparison of diagnostic yields between VCE and MR-enteroclysis in 52 consecutive patients with small bowel Crohn's disease was impaired due to bowel strictures in 14, who had to be excluded from capsule enteroscopy. Of the remaining 27 patients, VCE and MRI detected small bowel Crohn's disease in 93\% and 78\% respectively (45).

The highest diagnostic yield of small bowel radiologic studies is found in patients with obscure bleeding, but normal upper- and lower gastrointestinal tract endoscopies and with symptoms related to the tract. No other clinical parameter has been shown to be associated with a positive small bowel study (63).

\section{The future of VCE}

Although conventional endoscopic examinations, i.e. push-enteroscopy, and ileocolonoscopy, are less sensitive for revealing obscure small bowel lesions, these procedures will remain first line techniques due to their general availability and their provision of simultaneous treatment (67). Sonde-enteroscopy, as a method for examining the entire small bowel, is today replaced by VCE, whereas virtual enteroscopies based on CT and MRI, are still experimental. However, the VCE-system is undergoing rapid technical improvements that may relegate push-enteroscopy and intra-operative enteroscopy to those cases in which biopsies or therapy are required. At the same time enteroscopes for total enteroscopy are also improved and may become more widely available, allowing biopsies and therapy in all segments of the small intestine, without the need for operative intervention (68). A capsule technique for real time visualisation of the small bowel mucosa is recently launched. Furthermore, in the future, it is anticipated that the capsule may feature cytological and chemical sampling of the small bowel and be used for delivery of medication to specific disease sites (69).

The advent of double-balloon enteroscopy (70) has opened the field of endoluminal studies of the small bowel even further. However, the method is difficult to master and time-consuming, and therefore mainly used for endoscopic treatment of VCE findings. 
Clinical experience of the continuously improved wireless capsule for enteroscopy will soon establish its advantages and limitations in terms of sensitivity and specificity. It is expected that the number of cases with missed lesions due to retained intestinal debris, rapid and delayed transit of the small bowel and camera orientation away from a lesion will be reduced (71). A stricture that causes a downstream lesion to be missed at VCE may not be clinically relevant if the stricture requires surgery. Otherwise, accurate radiologic investigation will be required to characterize areas of narrowing seen at wireless capsule endoscopy (3)

\section{Summary}

The clinical importance of minute lesions and superficial mucosal breaks, without other signs of disease or ongoing bleeding, shown by VCE are being questioned as further characterization for a precise diagnosis is difficult or even impossible. Superficial ulcers and their precise location may in some instances be better characterized with double-contrast enteroclysis performed after wireless capsule endoscopy. In sporadic patients, VCE suggested Crohn's disease cannot be confirmed at subsequent enteroclysis or at surgery, and NSAID ulcers have been seen with double-contrast enteroclysis performed after a VCE with negative findings. Hence, in order to better localize lesions, to subtype different disease manifestations and to triage patients adequately to medical or surgical treatment, accurate radiologic investigation may still be required. Double contrast enteroclysis and CT enteroclysis will provide accurate information in certain patients (3).

With such single cases taken into account, the VCE is the examination of choice for the small bowel (72,73). The disposable capsule is readily ingested and allows for a complete, noninvasive endoscopic examination of the mucous membrane of the entire small bowel. It is a patient-friendly method for reliable detection of mucosal disorders and a first line procedure in the difficult evaluation of obscure gastrointestinal bleeding. It has the highest proven figure of diagnostic sensitivity for detecting lesions of the mucosa (figure 8) irrespective of aetiology (74). The only limitations of capsule endoscopy include difficulty in localizing mucosal lesions anatomically and its restricted use in patients with strictures or motor dysfunction. By choosing MRI as a complementary means in diagnosing small bowel Crohn's disease, transmural and extra-luminal lesions, as well as strictures, may be ruled in and ruled out (45). 


\section{References}

1. Maglinte DDT, Lappas JC, Kelvin FM, Rex D, Chernish SM (1987) Small bowel radiography: how, when, and why? Radiology 163:297-305

2. Ekberg O, Ekholm S (1980) Radiography in primary tumors of the small bowel. Acta Radiol Diagn 21:79-84

3. Maglinte DDT (2006) Capsule Imaging and the Role of Radiology in the Investigation of Diseases of the Small Bowel. Eur Radiol.; 16: 967-971

4. Lewis BS (1999) The history of enteroscopy. Gastrointest Endosc Clin N Am 9: 1-11

5. Iddan GJ, Swain CP (2004) History and development of capsule endoscopy. Gastrointest Endosc Clin N Am 14:1-9

6. Barkin J, Friedman S (2002) Wireless capsule endoscopy requiring surgical intervention: the world's experience (abstr). Am J Gastroenterol 97:S298

7. Lewis BS, Eisen GM, Friedman S: A pooled analysis to evaluate results of capsule endoscopy trials. Endoscopy 2005; 37: $960-965$

8. Marma R, Rotondano G, Piscopo R, Bianco MA, Cipolletta L: Meta-analysis: capsule enteroscopy vs. conventional modalities in diagnosis of small bowel diseases. Aliment Pharmacol Ther 2005; 22: 595-604

9. Triester SL, Leighton JA, LeontiadisGI, Fleischer DE, Hara AK, Heigh RI, Shiff AD, Sharma VK: A meta-analysis of the yield of capsule endoscopy compared to other diagnostic modalities in patients with obscure gastrointestinal bleeding. Am J Gastroenterol 2005;100:2407-2418

10. Pennazio M, Eisen G, Goldfarb N: ICCE consensus for obscure gastrointestinal bleeding. Endoscopy 2005; 37: 1046 - 1050

11. Apostolopoulos P, Liatsos C, Gralnek IM, Giannakoulopoulou E, Alexandrakis G, Kalantzis C, Gabriel P, Kalantzis N: The role of wireless capsule endoscopy in investigating unexplained iron deficiency anemia after negative endoscopic evaluation of the upper and lower gastrointestinal tract. Endoscopy 2006; 38: 1127-1132

12. Gurudu SR, Fleisher DE: From small-bowel bleeding to anemia: a wider range of indications for the capsule endoscope? Editorial. Endoscopy 2006; 38: 1144-1145 
13. Trieste SL, Leighton JA, Leontiadis GJ, Gurudu SR, Fleischer DE, Hara AK, Heigh RJ, Shiff AD, Sharma VR. A meta-analysis of the yield of capsule endoscopy compared to other diagnostic modalities in patients with non-stricturing small bowel Crohn's disease. Am J Gastroenterol 2006; 101: 954 - 964

14. Mosse CA, Swain CP (1999) Technical advances and experimental devices for enteroscopy. Gastrointest Endosc Clin N Am 9: 145 - 161

15. Iddan G, Meron G, Glukhovsky A, Swain P (2000) Wireless capsule endoscopy. Brief communications. Nature 405: 417

16. Eliakim R, Fireman Z, Gralnek IM, Yassin K, Waterman M, Kopelman Y, Lachter J, Koslowsky B, Adler SN (2006) Evaluation of the PillCam Colon capsule in the detection of colonic pathology: results of the first multicenter, prospective, comparative study. Endoscopy 38: 963-970

17. Cave DR (2004) Reading wireless video capsule endoscopy. Gastrointest Endosc Clin N Am $14: 17-24$

18. Eliakim RA (2006) Video capsule endoscopy of the small bowel (PillCam SB). Curr Opin Gastroenterol 22: 124-127

19. De Leusse A, Landi B, Edery J, Burtin P, Lecomte T, Seksik P, Bloch F, Jian R, Cellier C (2005) Video capsule endoscopy for investigation of obscure gastrointestinal bleeding: feasibility, results, and interobserver agreement. Endoscopy 37: 617-621

20. Niv Y, Niv G (2004) Capsule endoscopy: Role of bowel preparation in successful visualization. Scand. J. Gastroenterol 39: 1005-1009

21. Dai N, Gubler C, Hengstler P, Meyenberger C, Bauerfeind P (2005). Improved capsule endoscopy after bowel preparation. Gastrointest Endosc 61: 28-31

22. de Franchis R, Avgerinos A, Barkin J, Cave D, Filoche B (2005) ICCE consensus on bowel preparation and prokinetics. Endoscopy 37: 1040 - 1045 
23. Goldstein JL, Eisen GM, Lewis B, Gralnek IM, Zlotnick S, Fort JG (2005) Video capsule endoscopy to prospectively assess small bowel injury with celecoxib, naproxen plus omeprazole, and placebo. Clin Gastroenterol Hepatol 3: 133-141

24. Sturniolo GC, Di Leo V, Vettorato MG, D'Inca R (2005) Clinical relevance of small-bowel findings detected by wireless capsule endoscopy. Scand J Gastroenterol 40: 725-733

25. Lewis BS, Swain P (2002) Capsule endoscopy in the evaluation of patients with suspected small bowel bleeding: the result of a pilot study. Gastrointest Endoscop 56: 452-456

26. Pennazio M, Santucci R, Rondonotti E, Abbiati C, Beccari G, Rossini FP, De Franchis R (2004) Outcome of patients with obscure gastrointestinal bleeding after endoscopy: report of 100 consecutive cases. Gastroenterology 126: 643-653

27. Tang SJ, Haber GB (2004) Capsule endoscopy in obscure gastrointestinal bleeding. Gastroint Endosc 14: 87-100

28. Pennazio M, Eisen G, Goldfarb N (2005) ICCE consensus for obscure gastrointestinal bleeding. Endoscopy; 37: 1046-1050

29. Triester SL, Leighton JA, Leontiadis GI, Fleischer DE, Hara AK, Heigh RI, Shiff AD, Sharma VK (2005) A Meta-Analysis of the yield of capsule endoscopy compared to other diagnostic modalities in patients with obscure gastrointestinal bleeding. Am J Gastroenterol 100: 2407 2418

30. Malik A, Lukaszewski K, Caroline D, Parkman H, DeSipio J, Banson F, Bazir K, Reddy L, Srinivasan R, Fisher R, Miller L (2005) A retrospective review of enteroclysis in patients with obscure gastrointestinal bleeding and chronic abdominal pain of undetermined etiology. Dig Dis Sci 50: 649-655

31. Adler SN, Jacob H (2005) Occult inflammatory small-bowel disease: not so occult anymore. Scand J Gastroenterol 40: 360-364

32. Eliakim R, Adler SN (2004) Capsule video endoscopy in Crohn's disease-the European experience. Gastrointest Endosc Clin N Am 14: 129-137 
33. Ge ZZ, Hu YB, Xiao SD (2004) Capsule endoscopy in diagnosis of small bowel Crohn's disease. World J Gastroenterol 10: 1349-1352

34. Kornbluth A, Colombel JF, Leighton JA, Loftys E (2005) ICCE consensus for inflammatory bowel disease. Endoscopy 37: 1051-1054

35. Eliakim R, Fischer D, Suissa A, Yassin K, Katz D, Guttman N, Migdal M (2003) Wireless capsule video endoscopy is a superior diagnostic tool in comparison to barium follow-through and computerized tomography in patients with suspected Crohn's disease. Eur J Gastroenterol Hepatol 15: 363-367

36. Voderholzer WA, Beinhoelzl J, Rogalla P, Murrer S, Schachschal G, Lochs H, Ortner MA (2005) Small bowel involvement in Crohn's disease: a prospective comparison of wireless capsule endoscopy and computed tomography enteroclysis. Gut 54: 369-373

37. Fireman Z, Eliakim R, Adler S, Scapa E (2004). Capsule endoscopy in real life: a four-centre experience of 160 consecutive patients in Israel. Eur J Gastroenterol Hepatol.; 16: 927-931

38. Lomas DJ (2003) Technical developments in bowel MRI. (Review) Eur Radiol 13:1058-1071

39. Laghi A, Paolantonio P, Passariello R (2005). Small bowel (Review) Magn Reson Imaging Clin N Am 13:331-348.

40. Gourtsoyiannis NC, Papanikolaou N (2005) Magnetic resonance enteroclysis. (Review) Semin Ultrasound CT MR. 26:237-246.

41. Wiarda BM, Kuipers EJ, Houdijk LP, Tuynman HA (2005) MR enteroclysis: imaging technique of choice in diagnosis of small bowel disease. Dig Dis Sci 50: 1036-1040

42. Maglinte DD, Lappas JC, Heitkamp DE, Bender GN, Kelvin FM (2003) Technical refinements in enteroclysis. Radiol Clin North Am 41:213-222 
43. Romano S, De Lutio E, Rollandi GA, Romano L, Grassi R, Maglinte DD (2005) Multidetector computed tomography enteroclysis (MDCT-E) with neutral enteral and IV contrast enhancement in tumor detection. Eur Radiol 15:1178-1183

44. Horton KM, Fishman EK (2003) The current status of multidetector row CT and threedimensional imaging of the small bowel. Radiol Clin North Am 41: 199-212

45. Albert JG, Martiny F, Krummenerl A, Stock K, Lesske J, Gobel CM, Lotterer E, Nietsch HH, Behrmann C, Fleig WE (2005) Diagnosis of small bowel Crohn's disease: a prospective comparison of capsule endoscopy with magnetic resonance imaging and fluoroscopic enteroclysis. Gut 54:1721-1727

46. Schreyer AG, Seitz J, Feuerbach S, Rogler G, Herfarth H (2004) Modern imaging using computer tomography and magnetic resonance imaging for inflammatory bowel disease (IBD) Inflamm Bowel Dis 10:45-54

47. Eliakim R, Suissa A, Yassin K, Katz D, Fischer D (2004) Wireless capsule video endoscopy compared to barium follow-through and computerised tomography in patients with suspected Crohn's disease-final report. Dig Liver Dis 36: 519-522

48. Guilhon de Araujo Sant'Anna AM, Dubois J, Miron MC, Seidman EG (2005) Wireless capsule endoscopy for obscure small-bowel disorders: final results of the first pediatric controlled trial. Clin Gastroenterol Hepatol 3: 264-270

49. Arguelles-Arias F, Caunedo A, Romero J, Sanchez A, Rodriguez-Tellez M, Pellicer FJ, Arguelles-Martin F, Herrerias JM (2004) The value of capsule endoscopy in pediatric patients with a suspicion of Crohn's disease. Endoscopy 36:869-873

50. Goldfarb NI, Pizzi LT, Fuhr JP Jr, Salvador C, Sikirica V, Kornbluth A, Lewis B (2004) Diagnosing Crohn's disease: an economic analysis comparing wireless capsule endoscopy with traditional diagnostic procedures. Dis Manag 7: 292-304 
51. Schulmann K, Hollerbach S, Kraus K, Willert J, Vogel T, Moslein G, Pox C, Reiser M, Reinacher-Schick A, Schmiegel W (2005) Feasibility and diagnostic utility of video capsule endoscopy for the detection of small bowel polyps in patients with hereditary polyposis sybndromes. Am J Gastroenterol 100: 27-37

52. Soares J, Lopes L, Vilas Boas G, Pinho C (2004) Wireless capsule endoscopy for the evaluation of phenotypic expression of small bowel polyps in patiens with Peutz-Jeghers syndrome and in symptomatic first-degree relatives. Endoscopy 36: 1060-1066

53. Graham DY, Opekun AR, Willingham FF, Qureshi WA (2005) Visible small bowel intestinal mucosal injury in chronic NSAID users. Clin Gastroenterol Hepatol 3: 55-59

54. de Franchis R, Rondonotti E, da Silva Araujo Lopes LM (2004) Small bowel malignancy. Gastrointest Endosc Clin N Am 14: 139-141

55. Joyce AM, Burns DL, Marcello PW, Tronic B, Scholz FJ (2005) Capsule endoscopy findings in celiac disease associated enteropathy-type intestinal T-cell lymphoma. Endoscopy 37: 594596

56. Toth E, Ohlsson B, Ljungberg O, Thorlacius H (2006) Celiac disease diagnosed using video capsule endoscopy in a patient with Crohn's disease. Endoscopy 38:548

57. Cellier C, Green PHR, Collin P. Murray J (2005) ICCE consensus for celiac disease. Endoscopy 37: 1055- 1059

58. Cave D, Legnani P, de Franchis R, Lewis BS (2005) ICCE consensus for capsule retention. Endoscopy 37: 1065-1067

59. Leighton JA, Sharma VK, Srivathsan K, Heigh RI, McWane TL, Post JK, Robinson SR, Bazzell JL, Fleischer DE (2004) Safety of capsule endoscopy in patients with pacemakers. Gastrointest Endosc 59:567-569

60. Ell C, Remke S, May A, Helou L, Henrich R, Mayer G (2002) The first prospective controlled trial comparing wireless capsule endoscopy with push enteroscopy in chronic gastrointestinal bleeding. Endoscopy 34: 685-689 
61. Bouhnik Y, Coffin B, Moussaoui R, Oudghiri A, Rambaud JC (1998) Two way push videoenteroscopy in investigation of small bowel disease. Gut 43: 280-284

62. Mylonaki M, Fritscher-Ravens A, Swain P (2003) Wireless capsule endoscopy: a comparison with push enteroscopy in patients with gastroscopy and colonoscopy negative gastrointestinal bleeding. Gut 52: 1122-6

63. Rex DK, Lappas JC, Maglinte DD, Malczewski MC, Kopecky KA Cockerill EM (1989). Enteroclysis in the evaluation of suspected small bowel bleeding. Gastroenterology 97: 58-60

64. Lo SK (2004) Capsule endoscopy in the diagnosis and management of inflammatory bowel disease. Gastrointest Endosc Clin N Am 14:179-193

65. Maglinte DD, Kelvin FM, O'Connor $\mathrm{K}$ et al: Current status of small bowel radiography. Abdominal imaging 1996; 21: 247 - 257

66. Nolan DJ, Traill ZC. The current role of barium examination of the small intestine. Clin Radiol 1997; 52: 809 - 820

67. Saurin JC, Delvaux M, Vahedi K, Gaudin JL, Villarejo J, Florent C, Gay G, Ponchon T (2005) Clinical impact of capsule endoscopy compared to push enteroscopy: 1-year follow-up study. Endoscopy 37: 318-323

68. Lee SD, Cohen RD (2002) Endoscopy of the small bowel in inflammatory bowel disease. Gastrointest Endosc Clin N Am 12: 485-493

69. Rey JF, Ladas S, Alhassani A, Kuznetsov K, the ESGE Guidelines Committee (2006) European Society of Gastrointestinal Endoscopy (ESGE) Video capsule endoscopy: Update to guidelines (May 2006). Endoscopy 38: 1047 - 1053

70. Yamamoto H, Sekine Y, Sato Y, Higashizawa T, Miyata T, Iino S, Ido K, Sugano K (2001) Total enteroscopy with a nonsurgical steerable double-balloon method. Gastrointest Endosc 53:216-220

71. Hara AK, Leighton JA, Sharma VK, Heigh RI, Fleischer DE (2005) Imaging of small bowel disease: comparison of capsule endoscopy, standard endoscopy, barium examination, and CT. RadioGraphics 25: 697-718 
Capsule Enteroscopy and Radiology of the Small Intestine

72. Lewis BS, Eisen GM, Friedman S (2005) A pooled analysis to evaluate results of capsule endoscopy trials. Endoscopy 37: 960-965

73. Sturniolo GC, Di Leo Vincenza, Vettorato MG, De Boni M, Lamboglia F, De Bona Manuela, Bellumat A, Martines D, D'Inca Renata. (2006) Small Bowel Exploration by Wireless Capsule Endoscopy: Results from 314 Procedures. The American journal of Medicin 119: $341-347$

74. Eliakim R (2004) Wireless capsule video endoscopy: three years of experience. World J Gastroenterol. 10: 1238-1239 
Capsule Enteroscopy and Radiology of the Small Intestine

\section{Caption to figures}

1. Given M2A capsule indicating the main components: Lens and camera, batteries and the radio transmission device to the right.

2. The components of the Given capsule system: 1) Capsule, 2) external receiving antenna, 3) solid state data recorder and 4) carrying belt

3. Screenshot from the dedicated image reviewing software

4. Moderate size angiodysplasia without stigmata of ongoing bleeding

5. Crohns disease with fibrinous ulcerations of the mucosa

6. Adenomatous polyp in the jejunum in a patient with familial adenomatous polyposis

7. Typical mucosal scalloping in a patient with coeliac disease

8. White tipped villi in a patient with known intestinal lymphangiectasia 
Figures

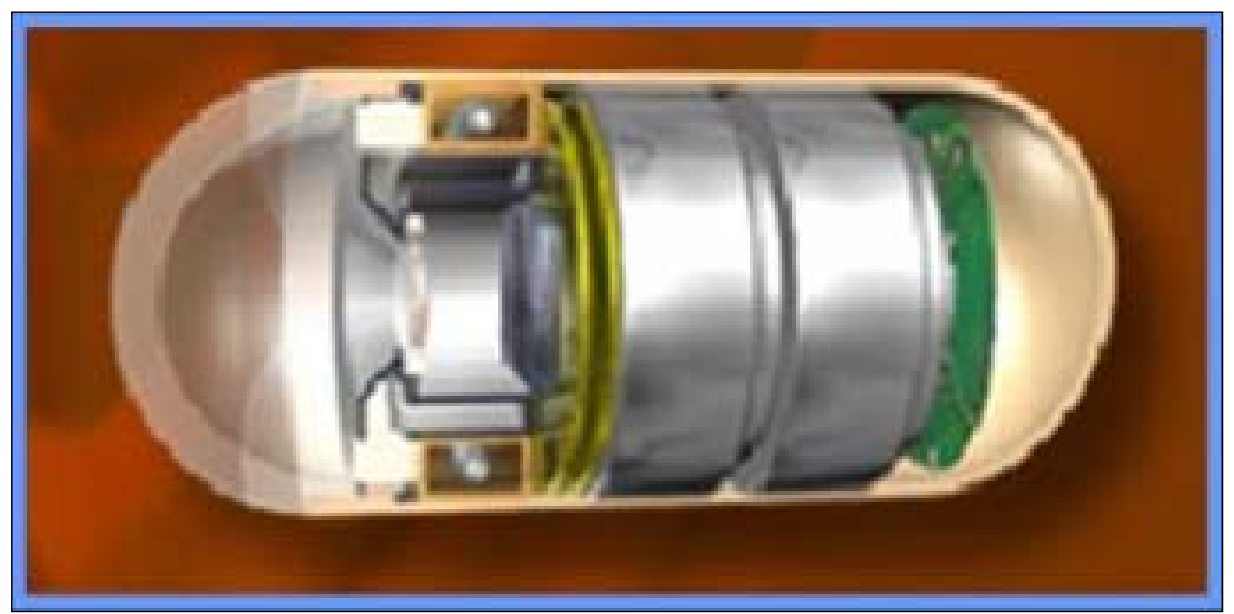

Fig 1

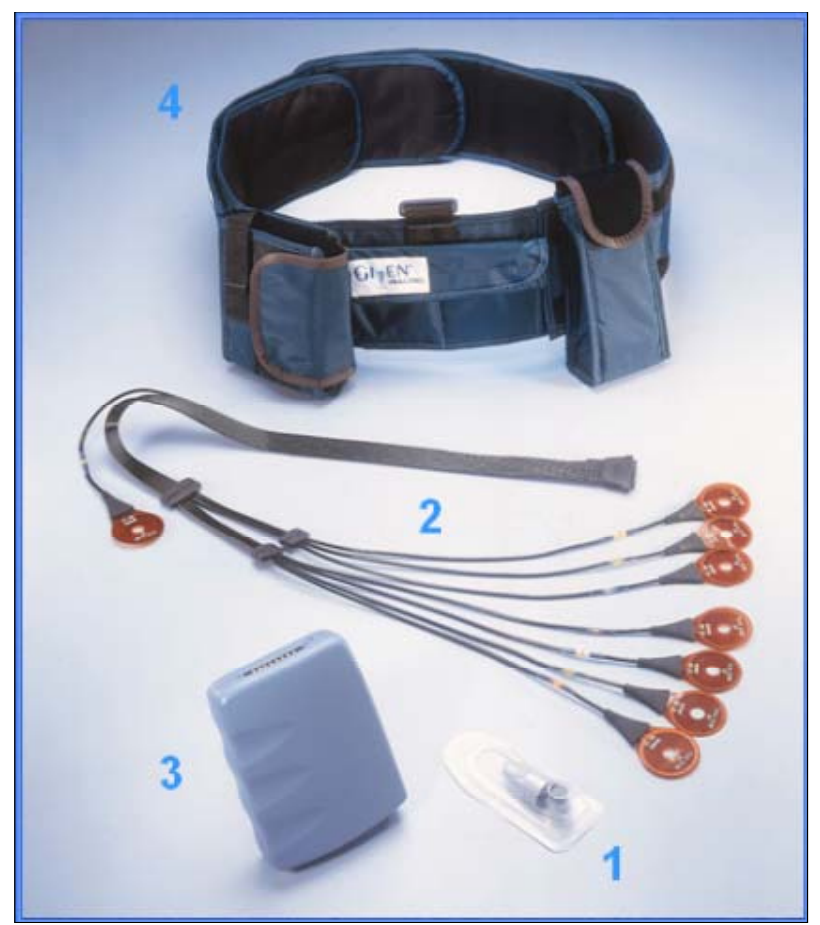

Fig 2 


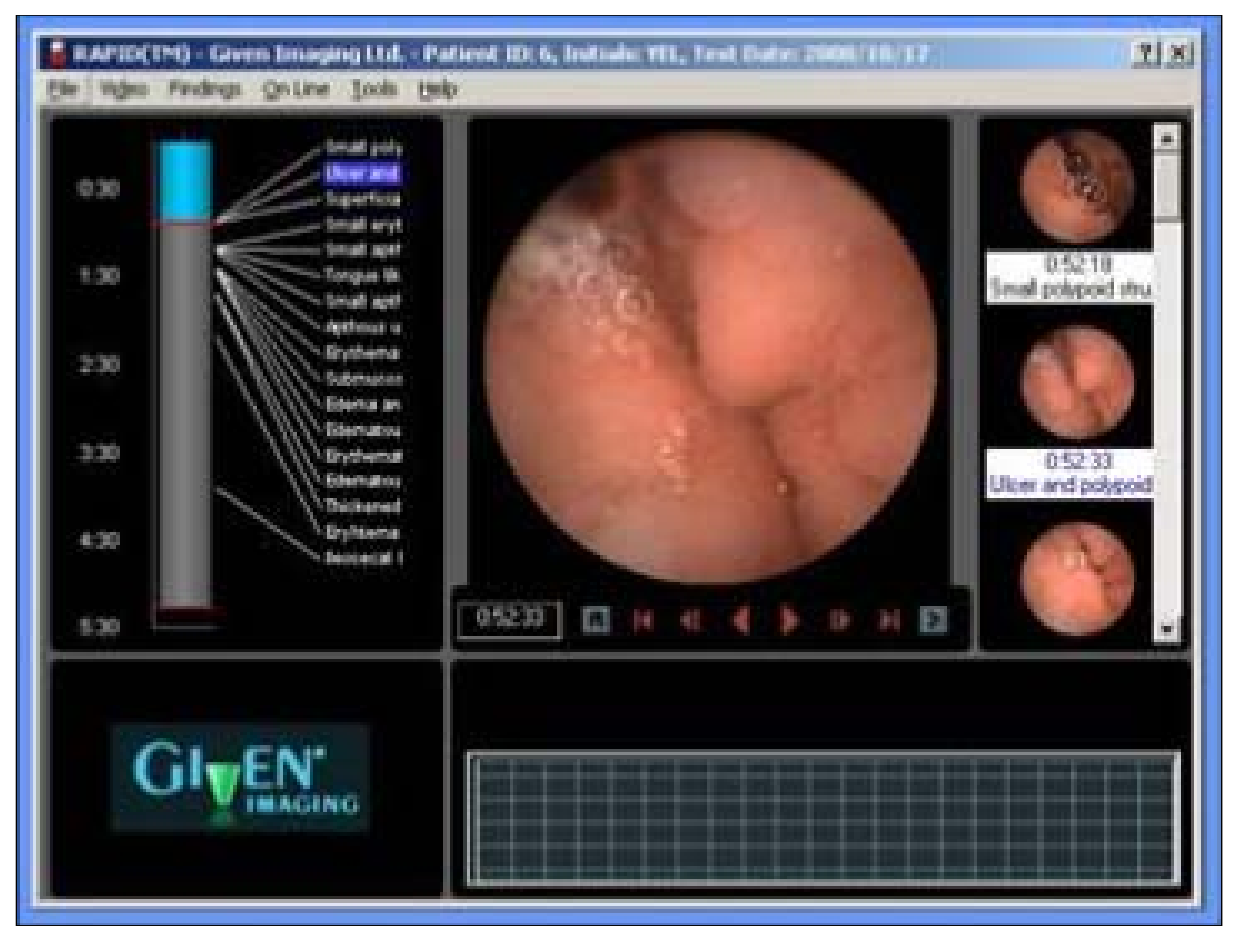

Fig 3

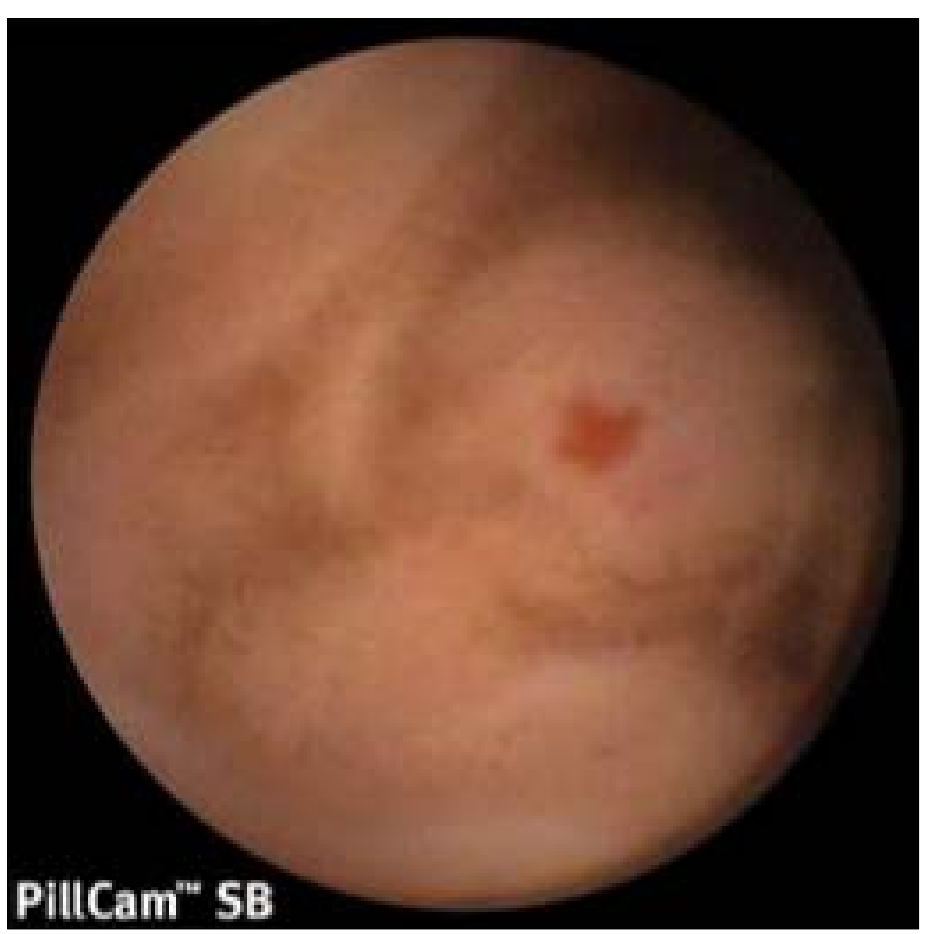

Fig 4 


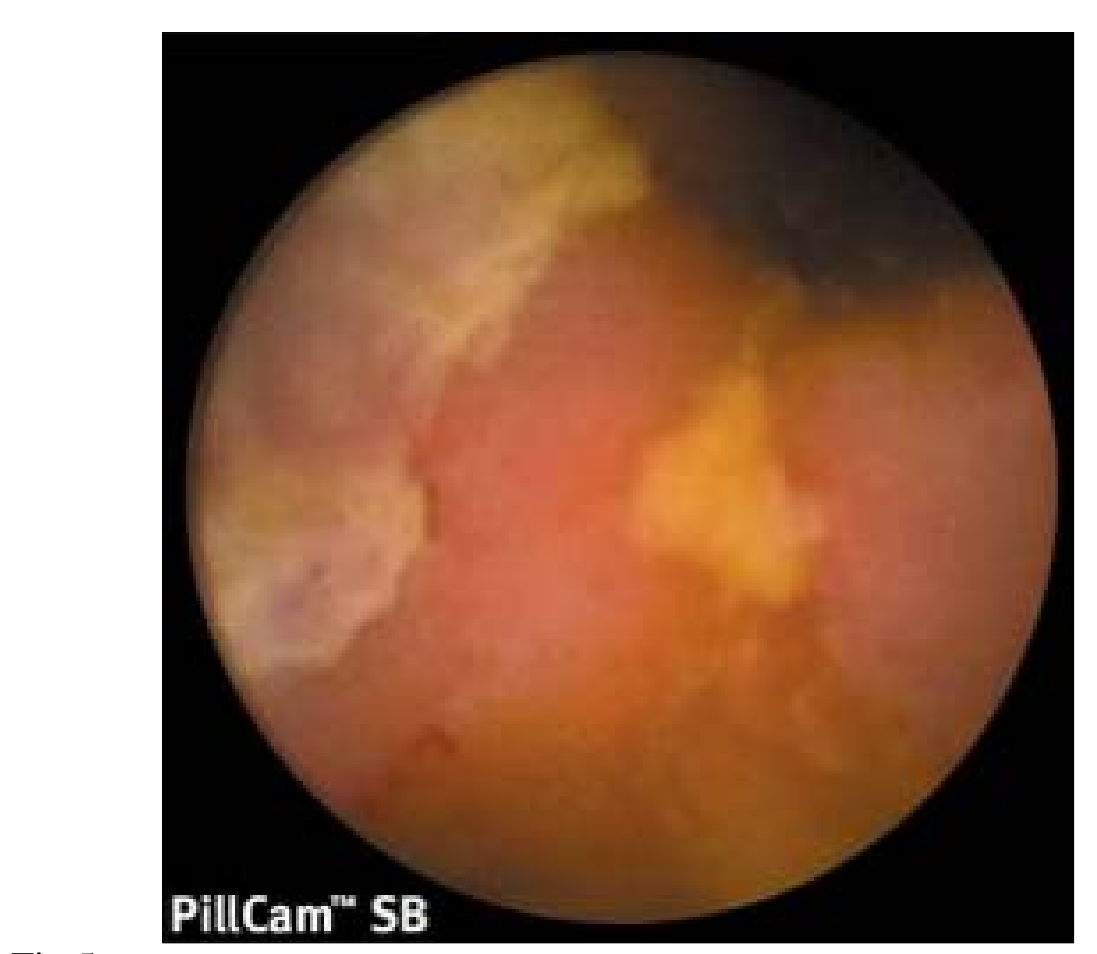

Fig 5

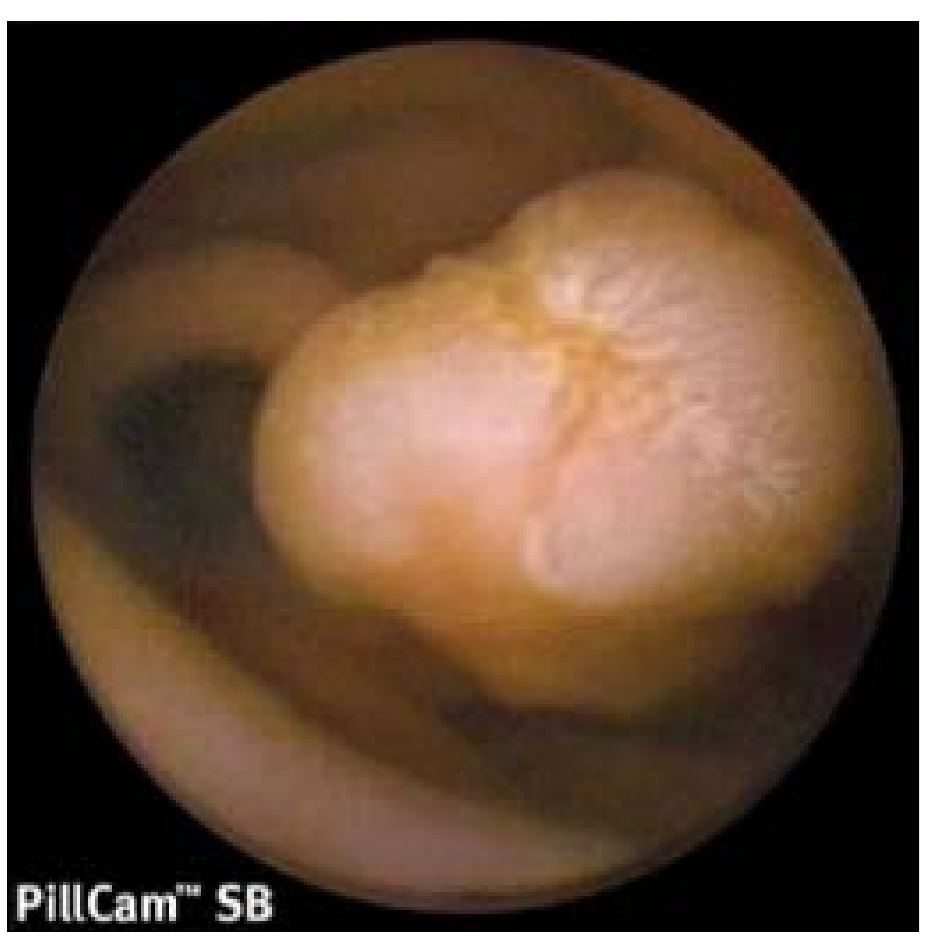

Fig 6 


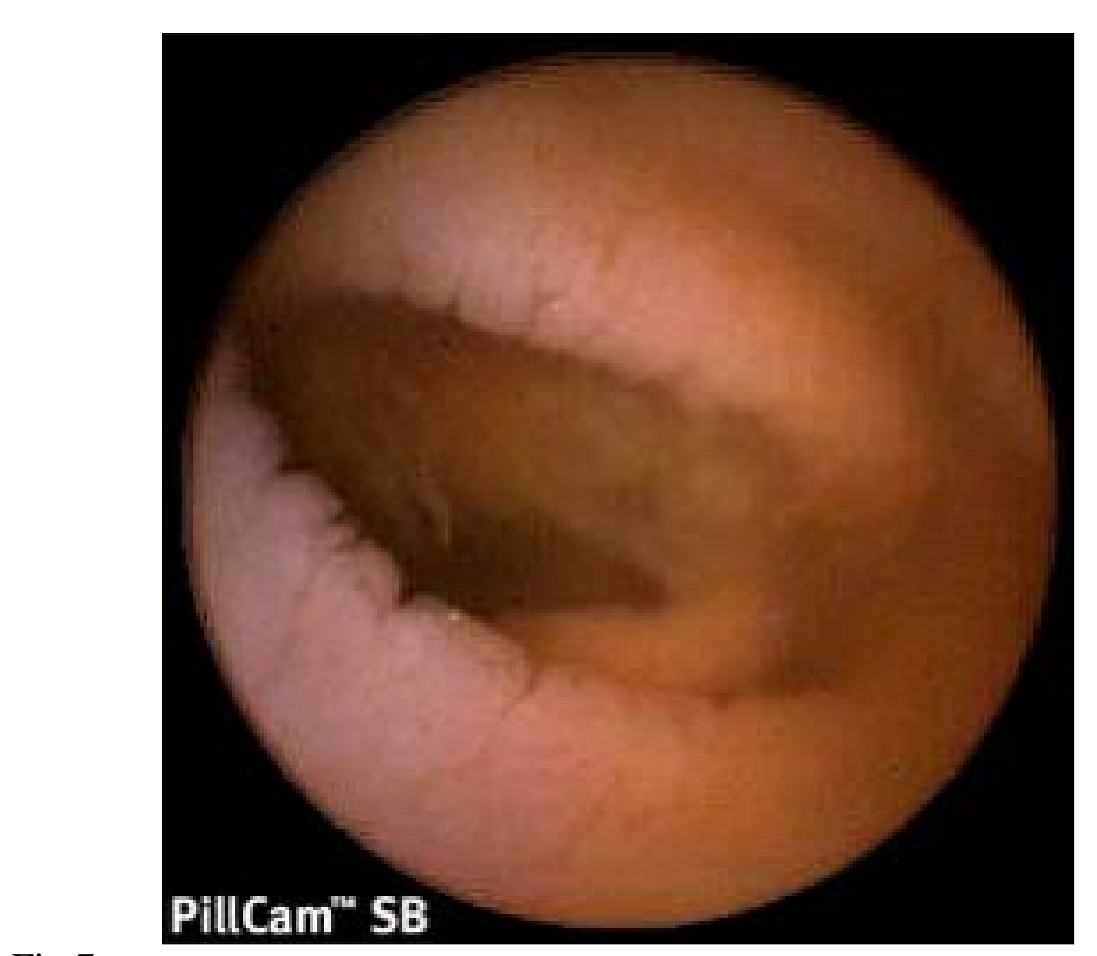

Fig 7

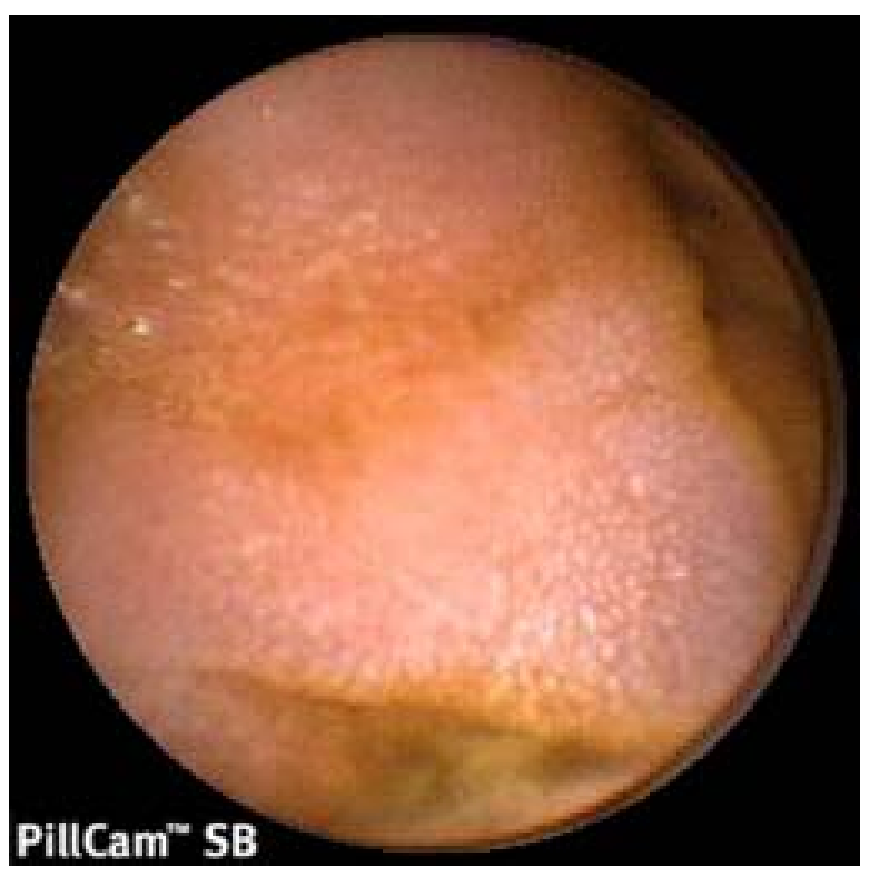

Fig 8 